\title{
Experimental Validation of the Corbella's Visibility Function using HUT-2D and MIRAS
}

\author{
F. Martin-Porqueras ${ }^{1}$, J. Kainulainen ${ }^{2}$, M. Martin-Neira ${ }^{3}$, I. Corbella ${ }^{4}$, R. Oliva ${ }^{3}$, R. \\ Castro $^{5}$, J. Barbosa ${ }^{5}$, and A. Gutierrez ${ }^{5}$ \\ SMOS Calibration Expert Center, European Space Agency, ESAC, Spain \\ ${ }^{2}$ Helsinki University of Technology, Finland \\ 3 \\ European Space Agency, ESTEC, The Netherlands \\ ${ }^{4}$ Polytechnic University of Catalonia, Spain \\ ${ }^{5}$ Deimos Engenharia, Portugal
}

Soil Moisture and Ocean Salinity (SMOS) is the ESA's Earth Observation mission intended for the measurement of the sea surface salinity and soil moisture by means of the L-band surface emissivity [1][2].

The spatial resolution requirements for passive imaging at L-band lead to large antenna apertures [3] for which arrays using aperture synthesis principles offer clear advantages mechanically and electronically to steered antennas and push-broom radiometers .

Although two-dimensional aperture synthesis has been used in radio-astronomy for several decades, its application to a downward-looking sensor for Earth observation is new [4] [5] and SMOS is the first space mission boarding an L-band Microwave Imaging Radiometer by Aperture Synthesis. During the MIRAS study, much has been learnt about two-dimensional aperture synthesis for Earth observation, and the results obtained with the airborne demonstrators and their calibration system thus far have demonstrated the technical feasibility of exploiting a spaceborne sensor of this type.

The main contribution of SMOS to the microwave aperture synthesis interferometry is the link between the microwave theory and the radio-astronomy theory. Both theories have been linked by means of the modification in the visibility function proposed by Prof. Corbella [6] which predicts that visibilities measured by an aperture synthesis radiometer are dependent to the difference between the target's brightness temperature and the backward noise of the receivers emitted through the antennas. In MIRAS, the backward noise is equal to the receivers' physical temperature since all the antennas include isolators and the formulation can be simplified to

$$
V_{i j}^{p q}(u, v) \equiv \frac{1}{\sqrt{\hat{\Omega}_{i} \hat{\Omega}_{j}}} \iint_{\xi^{2}+\eta^{2} \leq 1} F_{n, i}^{p}(\xi, \eta) F_{n, j}^{q^{*}}(\xi, \eta) \frac{T(\xi, \eta)-T_{r}}{\sqrt{1-\xi^{2}-\eta^{2}}} \widetilde{r}_{i j}\left(-\frac{u \xi+v \eta}{f_{o}}\right) e^{-j 2 \pi(u \xi+v \eta)} d \xi d \eta
$$

Where $V_{i j}^{p q}$ is the visibility between the receivers $i$ and $j$ in the polarization $\mathrm{p}$ and $\mathrm{q}$ respectively, $\Omega_{\mathrm{i}}$ is the solid angle of the antenna of the receiver $i, F_{i}(\xi, \eta)$ is the normalized antenna pattern of the receiver $i, T(\xi, \eta)$ is the brightness temperature of the scene, $T_{r}$ is the average physical temperature of the receivers, $r_{i j}$ is the fringe 
washing function between the receivers $i$ and $j,(\xi, \eta)$ are directing cosine coordinates and $(u, v)$ are the baseline coordinates expressed in wavelength

This equation corrects the traditional radio-astronomy theory where visibilities are proportional to the target's brightness temperature. For long baselines, the Corbella equation behaves as the traditional radio-astronomy visibility function.

During the SMOS development, measurements acquired by AMIRAS [7] and HUT2D [8] demonstrators have proved the validity of the visibility function proposed by Prof. Corbella. The method to experimentally validate the visibility function is measuring homogeneous targets since the visibility equation becomes directly proportional to the contrast between the brightness temperature of the target and the physical temperature of the receivers. In September 2004, AMIRAS measured the ceiling of an anechoic chamber and the cold sky [9], getting larger visibilities when imaging the Cold Sky as the Corbella equation predicts.

The validation conducted with HUT-2D using data acquired among several homogeneous targets will be presented. The measurements show a gradual increase with the contrast between the brightness temperature scene and the receivers' physical temperature.

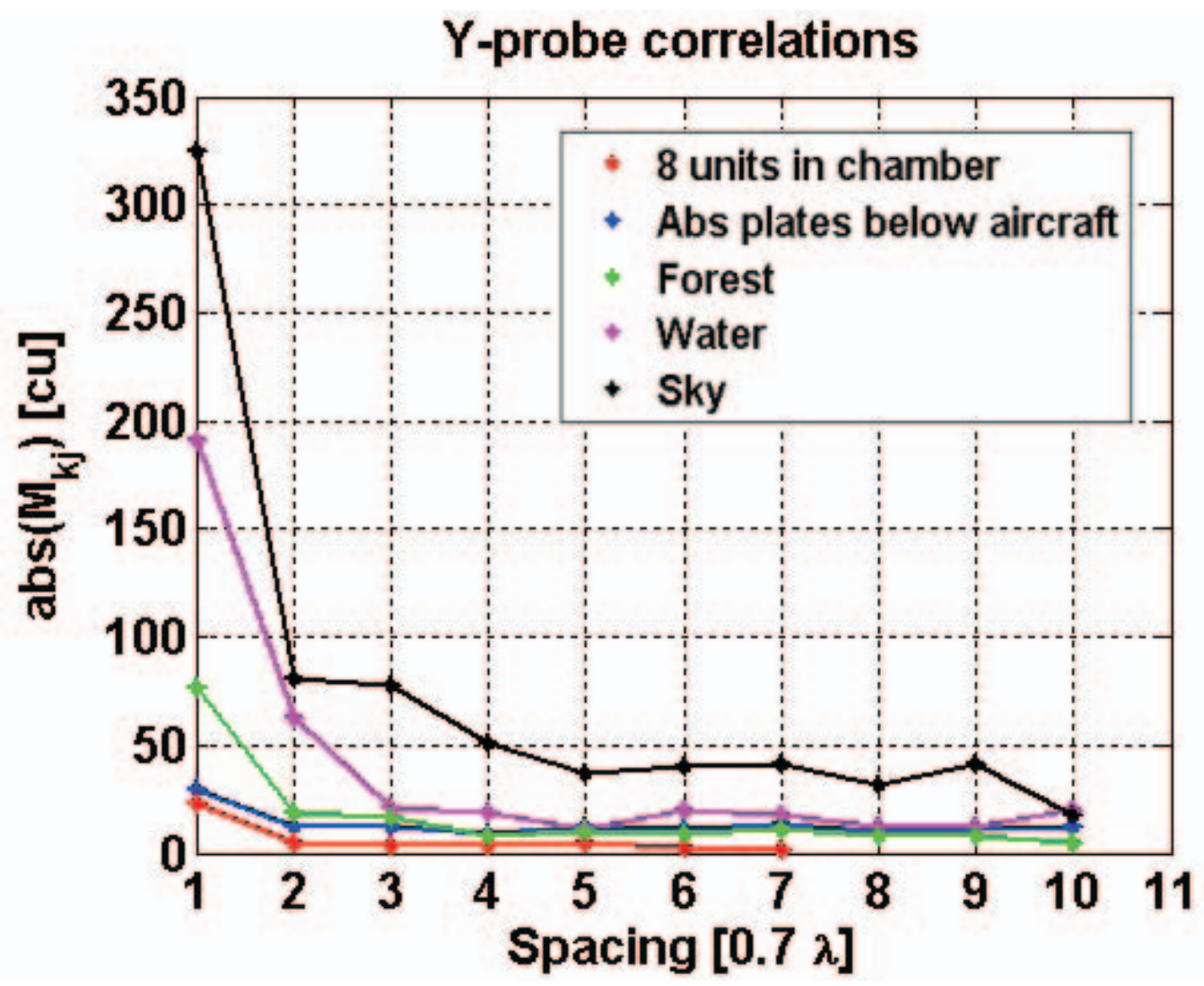

Figure 1 Measured correlations by HUT-2D on different homogeneous targets

After the successful launch of SMOS, MIRAS is also proving compatible measurements with the predictions of the Corbella equation. The Cold Sky 
measurements are larger than brighter scenes like the ones acquired in the anechoic chamber during the Image Validation tests conducted at ESA-ESTEC.

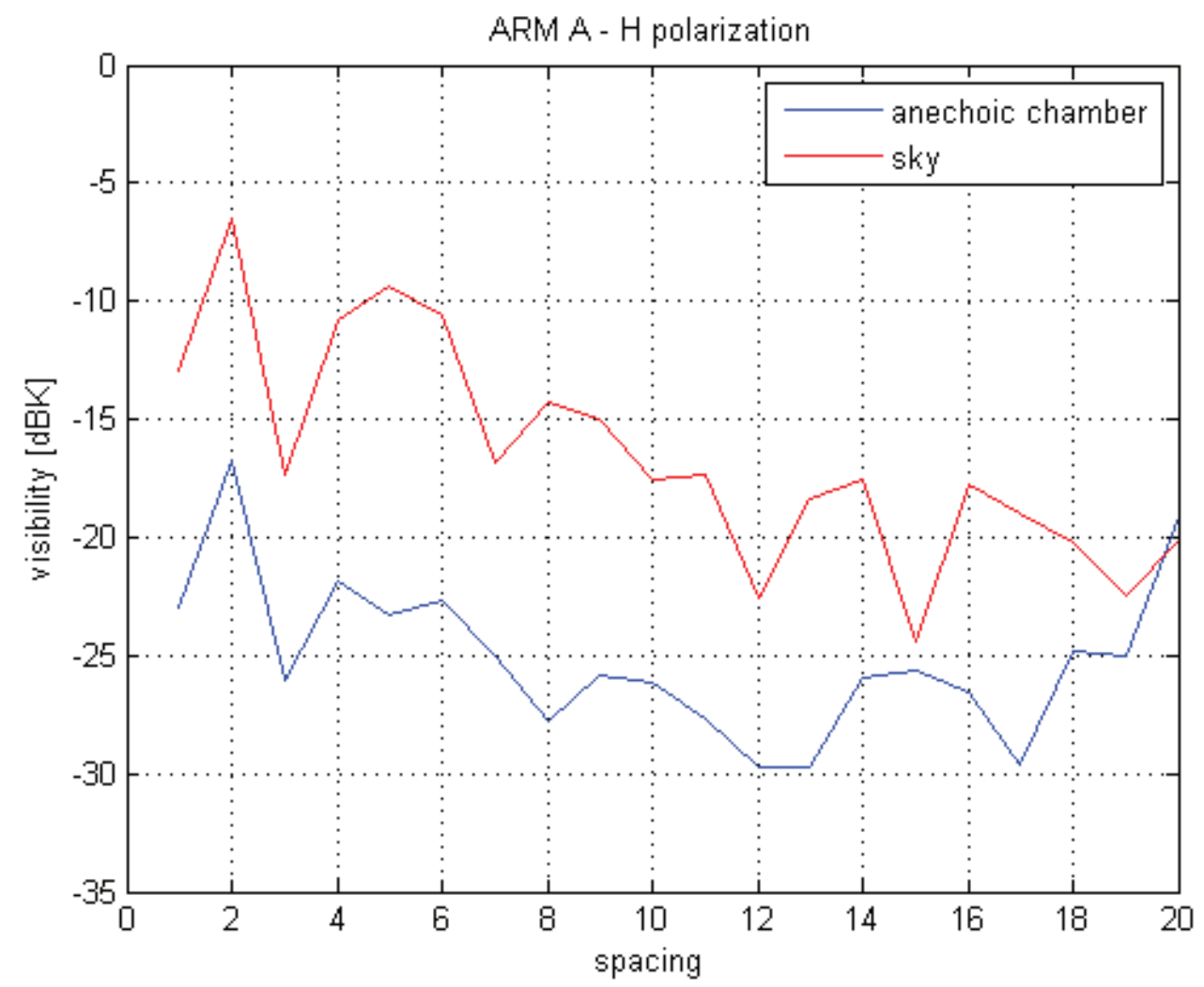

Figure 2 Calibrated visibilities measured by MIRAS pointing to the Galactic pole and the anechoic chamber

These last results obtained with HUT-2D and MIRAS will be presented together with a comparison between the classical visibility equation and the new formulation proposed by Prof. Corbella.

\section{References}

[1] Y. Kerr, P. Waldteufel, J. Wigneron, J. Martinuzzi, J. Font, and M. Berger, "Soil Moisture Retrieval from Space: The Soil Moisture and Ocean Salinity (SMOS) Mission," IEEE Trans. Geosci. Remote Sensing, vol. 39, no. 8, pp. 1729-1735, Aug. 2001

[2] J. Font, G. S. E. Lagerloef, D. M. Le Vine, A. Camps, and O. Zanifé, "The Determination of Surface Salinity With the European SMOS Space Mission," IEEE Trans. Geosci. Remote Sensing, vol. 42, no. 10, pp. 2196-2205, Oct. 2004.

[3] K. D. McMullan, M. A. Brown, M. Martín-Neira, W. Rits, S. Ekholm, J. Marti, and J. Lemanczyk, "SMOS: The Payload," IEEE Trans. Geosci. Remote Sensing, vol. 46, no. 3, pp. 594-605, Mar. 2008

[4] C. S. Ruf, C. T. Swift, A. B. Tanner, and D. M. Le Vine, "Interferometric synthetic aperture microwave radiometry for the remote sensing of the Earth," IEEE Trans. Geosci. Remote Sensing, vol. 26, no. 5, pp. 597-611, Sept. 1988. 
[5] A. J. Camps, "Application of interferometric radiometry to Earth observation," Ph.D. dissertation, Univ. Catalonia, Barcelona, Spain, Nov. 1996

[6] I. Corbella, N. Duffo, M. Vall-llossera, A. Camps, and F. Torres, "The Visibility Function in Interferometric Aperture Synthesis Radiometry," IEEE Trans. Geosci. Remote Sensing, vol. 42, no. 8, pp. 1677-1682, Aug. 2004.

[7] M. Martin-Neira, I. Cabeza, C. Perez, M. A. Palacios, M. A. Guijarro, S. Ribo, I. Corbella, S. Blanch, F. Torres, N. Duffo, V. Gonzalez, S. Beraza, A. Camps, M. Vallllossera, S. Tauriainen, J. Pihlflyckt, J. P. Gonzalez, and F. Martin-Porqueras, "AMIRAS-An airborne MIRAS demonstrator," IEEE Trans. Geosci. Remote Sens., vol. 46, no. 3, pp. 705-716, Mar. 2008.

[8] K. Rautiainen, J. Kainulainen, T. Auer, J. Pihlflyckt, J. Kettunen, and M. T. Hallikainen, "Helsinki University of Technology L-band airborne synthetic aperture radiometer," IEEE Trans. Geosci. Remote Sens., vol. 46, no. 3, pp. 717-726, Mar. 2008

[9] P. Moreno-Galbis, J. Kainulainen, and M. Martín-Neira, "Experimental Demonstration of the Corbella Equation for Aperture Synthesis Microwave Radiometry," IEEE Trans. Geosci. Remote Sens., vol. 45, no. 4, pp. 945-957, Apr. 2007 